\title{
Relation of Climatic Parameter on Tea Production in Organic Condition Specific to Assam
}

\author{
Pranab Dutta ${ }^{1,4^{*}}$, Himadri Kaushik ${ }^{1}$, R. P. Bhuyan ${ }^{2}$, Pranjal Kr. Kaman ${ }^{1}$, \\ Arti Kumari ${ }^{1}$, Apurba Das ${ }^{6}$ and H. K. Saikia ${ }^{7}$
}

${ }^{1}$ College of Agriculture, Department of Plant Pathology, ${ }^{2}$ Department of Tea Husbandry and Technology, ${ }^{3}$ College of Sericulture, Department of Agricultural Statistics, Assam Agricultural University, Jorhat-785013, Assam, India

${ }^{4}$ School of Crop protection, College of Post Graduate Studies in Agricultural Sciences, Central Agricultural University (Imphal), Umiam, Meghalaya-793103

*Corresponding author

\section{A B S T R A C T}

\section{Keywords}

Correlation,

Rainfall,

Temperature,

Relative humidity and Tea

Article Info

Accepted:

18 March 2020

Available Online:

10 April 2020
A study was conducted at tea growing regions of Assam to see the effect of climatic parameter on production of tea. Average production of tea started to diminish from 1992 and the trend had continued upto 2009. However, after 2010 the average production of tea started to increase. Results of correlation and regression analysis showed that except 'number of rainy days' other four variables (Temperature Range, Relative Humidity Range, Rainfall and Bright Sun Shine hours) are found to be significant. That means to maintain the increasing tea production trend we need to concentrate on Temperature Range, Relative Humidity, Range, Rainfall and Bright Sun Shine hours.

\section{Introduction}

The state of Assam is the world's largest teagrowing region, lying on either side of the Brahmaputra River, and bordering Bangladesh and Myanmar. This part of India experiences high precipitation; during the monsoon period, as much as 10 to 12 inches $(250-300 \mathrm{~mm})$ of rain per day. The daytime temperature rises to about $96.8 \mathrm{~F}$ $\left(36{ }^{\circ} \mathrm{C}\right)$, creating greenhouse-like conditions of extreme humidity and heat. This tropical climate contributes to Assam's unique malty taste, a feature for which this tea is well known.

The hundreds of lush green tea-gardens nestling in the Himalayan foothills of Assam 
have not only added charm to the states natural beauty but also form the backbone of its economy. They are the lifeline without which the state would have remained impoverished, undeveloped and economically at its lowest rung. Today tea industry of Assam constitutes its largest industry, providing livelihood, revenue, employment and development.

Tea was first discovered in China and then in Japan. Its origin in India dates back to 1823 when an Englishman named Robert Bruce discovered tea plants in the forests of Assam. Later Charles Alexander, Robert Bruce's brother started the first tea garden in Assam. In 1828, for the first time Assam tea was sent to England. It was liked by the Britishers and in no time it became very popular in England.

This encouraged the East India Company to start commercial cultivation of tea on a large scale. In 1835, the East India Company established its first tea garden in the state. Later in 1844 this garden was sold to Assam Tea Company which had been formed in 1839. Since then the number of tea gardens have increased by leaps and bounds. Today, there are over 900 tea gardens in Assam. These gardens are mostly found in the districts of Dibrugarh, Jorhat, Nagaon, Sivasagar, Sonitpur and Darrang.

The tea plant is grown in the lowlands of Assam, unlike Darjeelings and Nilgiris, which are grown in the highlands. It is cultivated in the valley of the Brahmaputra River, an area of clay soil rich in the nutrients of the floodplain. The climate varies between a cool, arid winter and a hot, humid rainy season conditions ideal for growing tea. Because of its lengthy growing season and generous rainfall, Assam is one of the most prolific teaproducing regions in the world. Each year, the tea estates of Assam collectively yield approximately 1,500 million pounds
$(680,500,000 \mathrm{~kg})$ of tea (TRA, 2015). The cultivation and production of Assam tea in the first two decades (1840-1860) were monopolised by the Assam Company, which operated in districts of Upper Assam and through the labour of the local community (Gokhale, 1998). The success of the company and the changes in colonial policy of offering land to the tea planters led to a period of boom and expansion in the Assam tea industry in the early 1860 s, but these could not necessarily be translated into a dramatic shift in production (from China to Assam) due to the "makeshift" nature of plantations, poor conditions of life on plantation (huge rates of mortality and desertion), and also at times the presence of pure speculative capital with no interest in tea production. Most of the tea estates in Assam are the members of which is the oldest and most prominent body of tea producers of India.

Assam tea is generally harvested twice, in a "first flush" and a "second flush". The first flush is picked during late March. The second flush, harvested later, is the more prized "tippy tea", named thus for the gold tips that appear on the leaves. This second flush, tippy tea, is sweeter and more full-bodied and is generally considered superior to the first flush tea. The leaves of the Assam tea bush are dark green and glossy and fairly wide compared to those of the Chinese tea plant. The bush produces delicate white blossoms.

Tea crops produced in northeast India are of major importance for the regional economy. India is the second largest producer and exporter of tea (Tea Board of India, 2014) with the northeastern state of Assam being a key producing region. The predominant tea variety produced in Assam is Assam-type var. Assamica (De Costa et al., 2007). On its own, Assam contributes around $17 \%$ of world tea production and annually produces more than $50 \%$ of India's tea (Dikshit and Dikshit, 
2014). Tea also plays a pivotal role in supporting the livelihoods of approximately 1.2 million laborers in Assam (Dikshit and Dikshit, 2014).

Climatic factors which include rainfall, temperature, humidity, intensity and duration of light etc., determine the success of crop production of a region. Of these perhaps rainfall and temperature play the most important role in the development and growth of plants and ultimately yield per unit area. For this rationale the study was conducted assess the present pattern of tea production and how microclimate (rainfall, temperature and humidity) impact on the productivity of tea leaf.

\section{Materials and Methods}

\section{Study area}

Banaspaty Tea Estate of tea promoters group on India is located at Karbi a long district of Assam (Fig. 1). The tea estate is following organic mode of cultivation since last 25-30 years.

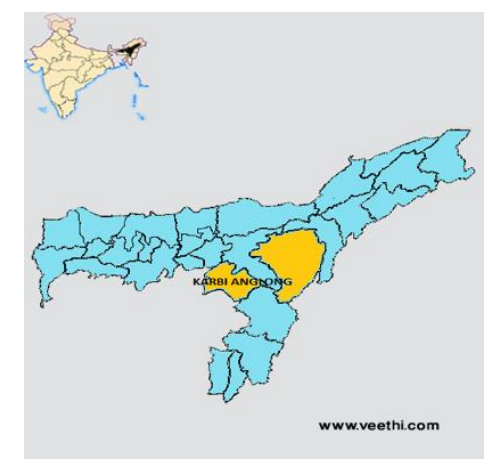

Fig.1 Study area

\section{Observance location and parameter recorded}

Thirty five years (1980- 2015) data on Rainy days, Temp Range, Relative Humidity Range, Rainfall and Bright Sun Shine hours were recorded.
The data was recorded on rainfall through rain gauge. The collected water was poured into a rain measure which was graduated in $10^{\text {th }}$ millimeters or in $10^{\text {th }}$ of 100 of an inch. The bottom of the measure was tapered to measure that small quantity accurately.

Humidity was recorded through dry and wet bulb in Celsius by following formula:

$\mathrm{WB}^{0} \mathrm{C}$ reading $-\mathrm{DB}^{0} \mathrm{C}$ reading = difference Humidity. Outcome of reading difference of humidity were checked in $\%$ from the table 1 available with the hygrometer kit.

Maximum / minimum temperature was recorded accordingly by using thermometer fixed in the wooden box. The direction of box was placed in the Agro-met weather station. All the equipments were installed properly at weather station. The data were recorded daily basis at 0900 hours accordingly (Anonymous, 1969).

Bright sunshine hours represent the total hours when the sunlight is stronger than a specified threshold, as opposed to just visible hours. Visible sunshine, for example, occurs around sunrise and sunset, but is not strong enough to excite the sensor. Measurement is performed by instruments called sunshine recorders.

Apart from the above mentioned parameters, we have also the information of monthly production of tea from Banaspaty Tea Estate for the period thirty five years (1980-2015). Based on this monthly production of tea data, we have calculated year wise average production of tea.

This is done basically to have an idea of the trend in terms of average production of tea from 1985 to 2015at Banaspaty Tea Estate. In Figure 2, the graphical representation shows that trend. 


\section{Results and Discussion}

It has been observed that average production of tea started to diminish from 1992 and the trend had continued up to 2009. However, from 2010 the average production of tea started to increase. In order to maintain that increasing trend, we need to identify the factors which are responsible for tea production. Thus, the following regression analysis has been performed. Except number of rainy days other four variables are found to be significant. That means to maintain the increasing tea production trend we need to concentrate on Temperature Range, Relative Humidity Range, Rainfall and Bright Sun Shine hours.

This ANOVA table (Table 2) $(\mathrm{p}<0.000)$ signifies that the regression analysis is fit for the data. However, the R-square value is 0.446 which means that the independent variable that we have considered, explained only $44.6 \%$ variation by the model.

The regression model for which the parameter needs to be estimated is -

Tea Production $=\mathrm{a}+\mathrm{b}_{1}$ Temp Range $+\mathrm{b}_{2} \mathrm{RH}$ Range $+b_{3}$ Rainfall $+b_{4}$ No. of Rainy Days $+b_{5}$ Bright Sun Shine Hours $+e$

Similar results were obtained by Boehm et al., 2016 where they have developed a multiple regression analysis of last eleven years data and found to be positively correlated with climatic parameter. The climatic parameters are Temperature Range, Relative Humidity Range, Rainfall and Bright Sun Shine hours which helps in increasing the production of tea . Ahmed et al., 2014 reported that tea production is highly effected by climatic parameters and they found that climatic parameters like, rainfall, number of rainy days, temperature, relative humidity, bright sunshine hours etc have been found to be positively correlated when regression analysis was performed based on 20 years of data. Patra et al., (2014) found positive correlation with relative humidity and total rainfall but found negatively correlated with temperature when compared with last nine years data.

\section{Temperature}

Bhagat et al., (2010)reported that temperature was the major environmental variable affecting the yield of tea, but within the framework of a temperature model shoot extension was severely depressed when daily maximum vapour pressure deficits above 2.3 $\mathrm{kPa}$. It was observed that day length did not affect shoot extension when the nights were cool $\left(10^{\circ} \mathrm{C}\right)$ but growth rate was depressed by short day when nights were warm $\left(20^{\circ} \mathrm{C}\right)$. Soil temperatures between 18 and $25^{\circ} \mathrm{C}$ did not affect shoot extension. Further, the soil temperature in the cold regions or during extreme winters can be modified by using mulching material.

Air temperature is also one of the important environmental factors for the growth of tea. Favorable temperature conditions alone cannot ensure its satisfactory growth unless other environmental factors remain congenial. Temperatures above $30^{\circ} \mathrm{C}$ and below $13^{\circ} \mathrm{C}$ are harmful for the growth of tea bush (Chakraborty and Srivastava, 1977)

\section{Bright sunshine hours}

Sunshine is needed for photosynthesis which can be relate to the vegetative growth of tea. Tea is a crop in which the yield is entirely based on vegetative and harvested throughout the year. Therefore change in weather conditions will affect the tea production. It has been reported by some workers that $6 \mathrm{hrs}$ of bright sunshine hour is needed for average tea production 


\section{Rainfall}

Changes in the monsoon season affect tea production because the quantity and variability of rainfall are crucial. Diminishing rainfall reduces tea yields, but this depends on its distribution over time. During long rains, tea production is lower when compared with short rains. This is due to long rainy periods reducing sunshine and the photosynthesis of tea leaves. Extreme rainfall events such as floods and droughts will also negatively affect tea yield (Esham and Garforth, 2013; Duncan et al., 2016). Wijeratne et al., (2007) found that a reduction of monthly rainfall by 100 $\mathrm{mm}$ could reduce productivity of made tea by30-80 kg/ha/month in Sri Lanka. The reduction in annual rainy days and relative humidity, which are closely correlated, will adversely affect tea production.

The highest tealeaf production per hectare depends on 4000-4600 mm annual rainfall, according to an analysis of field experiment results with weather data in Bangladesh (Ali et al., 2014).Tea generally exhibits a positive interaction between rainfall and temperature because its production depends on stable temperatures and consistent rainfall patterns (Ochieng et al., 2016). Any significant change in temperature and precipitation will affect production.

Table.1

\begin{tabular}{|l|c|c|c|c|c|}
\hline \multicolumn{1}{|c|}{ Model } & Sum of Squares & Df & Mean Square & F & Sig. \\
\hline Regression & 22853100063.957 & 5 & 4570620012.791 & 57.199 & .000 \\
\hline Residual & 28287359869.818 & 354 & 79907796.242 & & \\
\hline Total & 51140459933.775 & 359 & & & \\
\hline
\end{tabular}

Table.2

\begin{tabular}{|l|c|c|c|c|c|}
\hline \multicolumn{1}{|c|}{ Model } & \multicolumn{2}{|c|}{$\begin{array}{c}\text { Un-standardized } \\
\text { Coefficients }\end{array}$} & $\begin{array}{c}\text { Standardized } \\
\text { Coefficients }\end{array}$ & $t$ & Sig. \\
\cline { 1 - 6 } & B & Std. Error & Beta & & \\
\hline (Constant) & 16318.582 & 3838.782 & & 4.251 & .000 \\
\hline Temp Range & -1464.308 & 202.375 & -.393 & - & .000 \\
\hline RH Range & 62.920 & 25.403 & .104 & 2.477 & .014 \\
\hline Rainfall & 46.327 & 7.282 & .371 & 6.362 & .000 \\
\hline No. of Rainy Days & 104.231 & 71.090 & .069 & 1.466 & .143 \\
\hline $\begin{array}{l}\text { Bright Sun Shine } \\
\text { Hours }\end{array}$ & 1175.188 & 432.570 & .119 & 2.717 & .007 \\
\hline
\end{tabular}




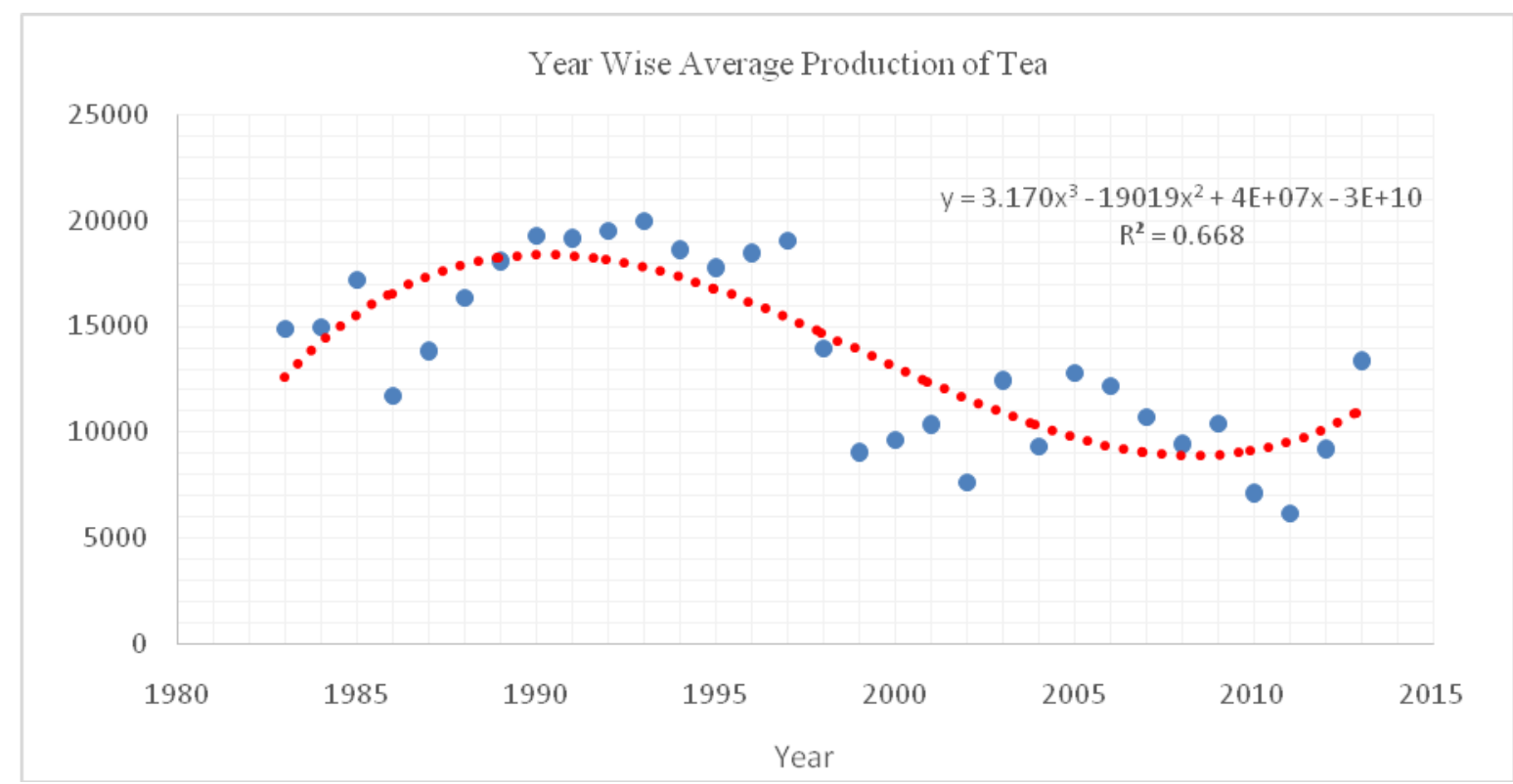

Fig.2 Tea production during thirty five years

Considering the socio-economic importance of the tea industry of Assam, it is important to implement adaptation measures in tea plantations, aiming at minimizing adverse impacts of climate without a delay, as it takes a considerable period of time to bring about changes to a tree crop system such as tea cultivation.

\section{References}

Ahmed, S., Stepp, J. R., Orians, C., Griffin, T., Matyas, C., Robbat, A. and Buckley, S. (2014). Effects of extreme climate events on tea (Camellia sinensis) functional quality validate indigenous farmer knowledge and sensory preferences in tropical China. PloS one, 9(10): 78-85

Ali, M., Uddin, M. N., Mobin, M. N. and Saha, N. 2014. Effects of microclimatic parameter on tea leafproduction in different tea Estates, Bangladesh. Journal of Environmental Science and Natural Resources. 7(1): 183-186

Anonymous. Tea Growers Hand Book, Tea Res. Inst. (TRI) Kericho, Kenya (1969) 76.
Bhagat, R. M., Baruah, R. D. and Safique, S. (2010) Climate and tea [Camellia sinensis(L.) o. Kuntze] production with special reference to North Eastern India: A Review. Journal of Environmental Research And Development4 (4): 10171028

Boehm, R., Cash, S. B., Anderson, B. T., Ahmed, S., Griffin, T. S., Robbat, A. and Orians, C. M. (2016). Association between empirically estimated monsoon dynamics and other weather factors and historical tea yields in China: results from a yield response model. Climate 4 (2): $20-28$

Carr, M. K. V. and Stephens, W. (1992). Climate, weather and the yield of tea. In Tea pp. 87-135. Springer, Dordrecht.

Chakraborty S. and Srivastava A.K. (1977) Biochemical interpretation for the quality deterioration in rains tea.Two and Bud. 24 (2): 31-32

De Costa, W. A., Mohotti, A. J. and Wijeratne, M. A. (2007). Ecophysiology of tea. Brazilian Journal of Plant Physiology.19(4): 299-332.

Dikshit, K. R. and Dikshit, J. K. (2014). North-east India: Land, people 
and economy. Dordrecht: Springer.

Duncan, J. M. A., Saikia, S. D., Gupta, N. and Biggs, E. M. (2016). Observing climate impacts on tea yield in Assam, India. Applied Geography, 77: 64-71.

Esham, M. and Garforth, C. 2013. Climate change and agricultural adaptation in Sri Lanka: A review.Climate and Development 5: 66-76.

Gokhale, N. A. (1998). The hot brew: the Assam tea industry's most turbulent decade,.Spectrum Publications. 4: 120135

Ochieng, J.,Kirimi, L. and Mathenge, M. 2016. Effects of climate variability and change on agricultural production: The case of small scale farmers in Kenya. Wageningen Journal of Life Sciences. 77: 71-78.

Patra, P. S., Bisen, J. S., Kumar, R., Choubey,
M., Mazumdar, A. B., Singh, M. and Bera, B. (2013). Effect of climate change on production of Darjeeling tea: a case study in Darjeeling tea research and development centre, Tea board, Kurseong. Global Journal of Biology Agriculture Health and Science 2: 174180.

Tea Board of IndiaGlobal tea statistics (2014) http://www.teaboard.gov.in/pdf/Global_ Tea.pdf/

Wijeratne, M. A., Anandacoomaraswamy, A., Amarathunga, M. K. S. L. D., Ratnasiri, J. and Basnayake, B.R. S. B. (2007). Assessment of impact of climate change on productivity of tea (Camellia sinensisL.) plantations in Sri Lanka. Journal of the National Science Foundation of Sri Lanka. 35(2):119126.

\section{How to cite this article:}

Pranab Dutta, Himadri Kaushik, R. P. Bhuyan, Pranjal Kr. Kaman, Arti Kumari, Apurba Das and Saikia, H. K. 2020. Relation of Climatic Parameter on Tea Production in Organic Condition Specific to Assam. Int.J.Curr.Microbiol.App.Sci. 9(04): 2243-2249. doi: https://doi.org/10.20546/ijcmas.2020.904.269 